\title{
Minutes of the 2019 CAML/ACBM Annual General Meeting
}

\section{Canadian Association of Music Libraries, Archives and Documentation Centres (CAML) L'Association canadienne des bibliothèques, archives et centres de documentation musicaux (ACBM)}

Friday, June 7, 2019, 12:30 PM

Rm 116 School of Music, University of British Columbia

\section{(As approved at the CAML AGM, June 5, 2020)}

\section{Attendees}

In Attendance: Houman Behzadi, Carolyn Doi, Becky Smith, Tim Neufeldt (skype), Katherine Penner, Margaret Piper, Marc Stoeckle, Monica Fazekas, Kirsten Walsh, Desmond Maley, Janneka Guise, Deborah Wills, Brian McMillan, Laura Snyder, Lucinda Johnston, Sean Luyk, Homer Seyward

Regrets: Kyla Jemison, Kevin Madill, James Mason

\section{Call to order: 12:43 PM}

1) Approval of Agenda: Moved - Monica Fazekas, Second - Kirsten Walsh (Carried)

2) Approval of Minutes from 2018 AGM: Moved - Houman Behzadi, Second - Laura Snyder (Carried)

3) Business Arising from the Minutes: none.

4) Reports

a. President's report (Carolyn)

i. Acknowledgement that we are on ancestral unceded Musqueam, Squamish, and Tsleil-Waututh territory, and thankful for ability to learn here.

ii. Thank you to Marc and Kevin for organizing program. Feedback for volunteers doing program and local arrangements - the procedures manual will continue to be updated.

iii. Board Membership - Thank you to all the volunteers working with CAML over the year. Many changes over this year, thank you to all!

1. James will be stepping down as Communications officer, and Marc Stoeckle will take over (as appointed by president and approved by board). 
2. Katherine's position as secretary will expire effective at AGM. A call has been issued to membership by our new nominations' secretary, Kyla Jemison.

iv. $\quad 2018$ IAML meeting

1. Copyright Committee Meeting: Scott Macdonald completed responses on behalf of CAML for the report presented, and full report will be available soon via IAML website

2. Attended IAML National Representatives meeting

v. IAML Election happening and we have two members up for positions on IAML Board: Joseph Hafner \& Jan Guise

vi. NY/Quebec Joint chapter meeting in Montreal - many topics covered, and a report was published in the CAML Review

vii. CAML Review - Overview of publication provided. Cathy Martin (editor) \& Brian Thompson (review editor) will both be stepping away from their roles this year, with Cathy willing to stay on until the position is filled. Calls have been made for both positions. Any interested applicants are encouraged to ask questions about the work done. Thank you to all those who have been doing the work of producing the CAML review.

b. Treasurer's Report (Tim Neufeldt)

i. After taking over from Rob, these presented budgets are a hybrid between Rob and Tim's documentation styles. Speaking to submitted report:

ii. 2018 budget:

1. Have added conference speaker fees and $\$ 1000$ donation to joint meeting

2. Question from Audit Committee: Why do we have a deficit in Conference 2018?

3. Answer (TN): We usually make money, but we actually owed this past year because of low attendance

iii. 2019 budget:

1. Web fees look like $\$ 2000$, but in addition to this, this will be $\sim \$ 2370$ after renewal and refund to James.

2. Conference costs still need to be finalized.

iv. 2020 budget:

1. We have about $\$ 6500$ in the bank now

2. We have a concern that our expenses are substantially higher than our income, but this is a conservative estimate, and will likely even out a bit more with new memberships. We do have the GIC to pull us through if needed 
3. Suggestion (Desmond): take an estimate for conference deficit from average of last 5 years

4. Question (Lucinda): What are member expenses?

5. Answer (various): Costs incurred by members needing to travel on behalf of CAML

6. Question (Desmond): Should we look into hold off on award funding pending our bank acct, and how much is in the acct?

7. Answer (TN): The proposed budget will not be putting us in the red because we have the GIC, and it is unlikely that we will spend all the award money.

v. MOTION TO ACCEPT the report: (Motion) Desmond, (Second) Brian (carried)

c. Audit Committee's report (Brian/Monica)

i. Two new members and a new treasurer

ii. Audit committee reviewed docs on June $6^{\text {th }}$.

iii. All questions have been answered in meeting with treasurer, and recommendations are as follows:

1. Committee recommends stated provision of report 30 days in advance

2. Provide monthly statements

3. Provide differentiation between bank and PayPal

4. Pay invoices asap, though it is recognized that there is delay between the transfer between board members

iv. Question (Jan): Would it be helpful for the treasurer and the audit committee if there was a 6-month check-in to help the new members of the committee?

v. Answer (Brian \& Tim): Yes, we'll look at the Terms of Reference and add to the Procedures Manual

ACTION: Treasurer to add this to Procedures Manual

d. Membership Secretary's report (Becky)

i. Following Kyla's past documentation style

ii. Same total number of members as 2017, but numbers for this year are only until May.

iii. 11 new memberships

iv. 1 donation from membership page

v. We may also run a membership drive later in the year.

vi. Question (Desmond): Who are the new members?

vii. Answer (Becky): No names provided here, but mainly students. (Desmond)

Where I was going with this is that maybe we should send out a letter about 
what CAML is about. (Brian) This was something done in the past, typically taken on by the President.

e. Communication Officer's Report (James/Marc)

i. New website is underway, modernizing the website

1. There isn't an official timeline for the release right now, but we still have to find content

2. Also considering an update to the logo. Would like to see if there is any input about updating the logo.

3. Question (Monica): What process do you want to undertake for this?

4. Answer (MS): We don't have budget, but I have design background. I personally think this would make a positive impact on our brand to help with membership.

5. Question (Monica): Is it a re-branding, or just a logo?

6. Answer (Carolyn): the Board has not discussed a change to the mission of the board or association. This is a discussion about the logo on the website.

7. Answer (MS): I'm getting the feeling we're not having a lot of pushback on this, so we'll go ahead.

8. Comment (Deborah): Thank you for being willing to take this on.

9. Comment (Jan): I like the idea of getting a limited number of options to choose from. We may be able to use the online voting system!

10. Answer (MS): This is just a first step in the role I can do now. I feel confident that you'll all love the website.

f. CAML Review report (Carolyn for Cathy)

i. See "CAML Review" in President's report above

g. Nomination Officer's Report (Carolyn for Kyla)

i. Kyla received one expression of interest for Secretary position, and Lucinda Johnson ( $U$ of Alberta) is acclaimed the new CAML Secretary.

h. Cataloguing Committee report (Carolyn for Daniel)

i. Daniel will be stepping down from this chair position after many years of service. If anyone is interested in taking on the chair or become part of the committee, they're encouraged to connect with any member of the committee. There is always room for additional members.

ii. Thank you to Daniel for his service. We have all benefitted greatly from his contribution.

i. R Reports

i. RISM (Houman for Kyla) - Kyla has agreed to be the RISM coordinator. Houman will connect with Kyla to make sure she has the connections she 
needs. When Creighton Barrett from Dalhousie is back from leave, he will join them. Creighton is also willing to work as a resource for us.

ii. RILM (Houman - no coordinator in place) - If anyone is interested, they can connect with either Houman or Sean with questions.

iii. RIPM (Houman - no coordinator in place) - no work at this time

j. Québec Chapter report (Carolyn for Rachel)

i. As submitted

k. Awards Committee report (Margaret)

i. Committee Members: Margaret, Marc, Lelland

1. Research award: changed to research and professional development award.

2. Cheryl Martin award: extended to new librarians

3. More active outreach

a. We'll be sending out the calls for awards a bit earlier, though word of mouth is key for getting applicants.

b. This year we only gave one award: First time attendee (Jessica Tse)

c. Question (Monica): Did you send to student associations, listservs, and library schools?

d. Answer (Marc): Yes. (Margaret): We will be earlier next year.

e. Question (Desmond): When did the call go out?

f. Answer (Margaret): Soon after the CfP.

g. Comment (Brian): Considering our timelines and high turnover, we should just make sure this timeline is updated in the Procedures Manual.

h. Answer (Marc): A shared "live" procedures manual would be extremely helpful.

i. ACTION: Margaret to look at what needs to be updated in Procedures Manual.

I. MOTION TO ACCEPT REPORTS: Moved - Monica; Second - Jan (carried)

5) Conference $2020 @ W e s t e r n$ (London, ON)

a. Comment (Sean Luyk): Feel strongly that we should meet with Congress, as there are many other options for everyone to attend, and we should meet with Congress regardless of where MusCan meets.

b. Comment (Brian): We are very happy to welcome you to London, and we are already looking into spaces and restaurants for our meeting.

c. ACTION: Houman to connect with MusCan about meeting with Congress

d. ACTION: Houman and Carolyn to connect with possible local arrangements colleagues at Western 
6) Other Business

a. Revision of Constitution to include Collections Committee

i. MOTION THAT THE CONSTITUTION BE AMENDED to incorporate the Collections Interest Group as a permanent standing committee of CAML. (Second) Becky (Carried)

7) Passing of CAML Helmut Camel from outgoing to incoming president: Carolyn to Houman 8) Meeting Adjourned: Moved - Brian 